\title{
Nasofrontal dermal sinus with intradiploic epidermoid cyst: case report
}

\begin{abstract}
Nasofrontal dermal sinuses are very rare and generally occur in children. This congenital malformation can be revealed by midface swelling, local infection or neuromeningitis which make it a life-threatening disease. The case of a two-year-old boy who presented with spontaneously regressive orbitonasal soft tissue swelling is presented. Physical examination found a puncture hole letting out thick yellow substance at the nasal base. Computed tomography revealed a thickening of subcutaneous soft tissue and a frontal bone defect. Magnetic resonance imaging showed atrans-osseous tract with an Intradiploiccyst. The patient underwent a total excision of her dermal sinus along with the resection of the cyst via a trans-facial approach. The inner bone layer of the skull was intact. Pathological examination confirmed the diagnosis of dermal sinus associated with an Intradiploic epidermoid cyst. The postoperative course was uneventful.
\end{abstract}

The case reported in this article represents a genuine example of the possible association of a nasofrontal dermal sinus with an Intradiploic epidermoid cyst and that a trans-facia approach is suitable to address the two lesions at the same time with good cosmetic result.
Volume I Issue 4 - 2014

\author{
Ben Nsir A, Hadhri M, Boughamoura M, \\ Kilani M, Hattab N \\ Department of Neurological Surgery, Fattouma Bourguiba \\ University Hospital,Tunisia
}

\begin{abstract}
Correspondence: Atef Ben Nsir, Department of Neurological Surgery, Fattouma Bourguiba University Hospital, Monastir 5 , Tunisia, Tel +216-40177077, Fax +216-73460309.
\end{abstract} Email atefbn@hotmail.fr

Received: July 19, 2014 | Published: August 28, 2014

Keywords: Dermal sinus, Epidermoid cyst, Magnetic resonance imaging, Surgery

Abbreviations: CT, Computed Tomography; MRI, Magnetic Resonance Imaging

\section{Introduction}

A cranial dermal sinus results from faulty regression of the embryologic dural diverticulum from the prenasal space ${ }^{1} \mathrm{~A}$ Nasofrontal skin dimple may be located anywhere between the glabella and the columella of the nose, and it continues as a dermal sinus into the cranium through a bone defect. ${ }^{2}$

A dermoid, or more rarely an epidermoid, cyst may develop along the course of the dermal sinus. ${ }^{2}$ This connection between the skin surface and the brain may cause secondary local infection, especially orbitonasal, or more seriously, meningitis. ${ }^{1}$

We report a rare case of a dermal sinus associated to an Intradiploic epidermoid cyst revealed by a spontaneously regressive soft tissue swelling and discuss the potential pitfalls in the diagnosis and the management of this rare condition.

\section{Case presentation}

A two-year-old boy was addressed for a spontaneously regressive orbitonasal soft tissue swelling. He was born full-term and weighed $3.4 \mathrm{~kg}$ at birth with a height of $49 \mathrm{~cm}$ parents found a clear fluid seeping from a puncture hole located at the nasal base. As the fluid seeping became progressively yellow and thick, he presented several episodes of spontaneously regressive orbitonasal swelling without inflammatory signs.

Physical examination found a puncture hole at the nasal base (Figure 1). Neurological examination was normal. Computed tomography $(\mathrm{CT})$ was performed to search any intracranial or orbital extension. It revealed thickening of the subcutaneous soft tissue and an anterior midline defect of the cranialvault (the anterior neuropore (Figure 2). Magnetic resonance imaging (MRI) delineated better the CT findings with an intradiploic epidermoid cyst displaying a hypointense signal on T1- and T2-weightedmagnetic resonance (MR) images without contrast enhancement (Figure 3).

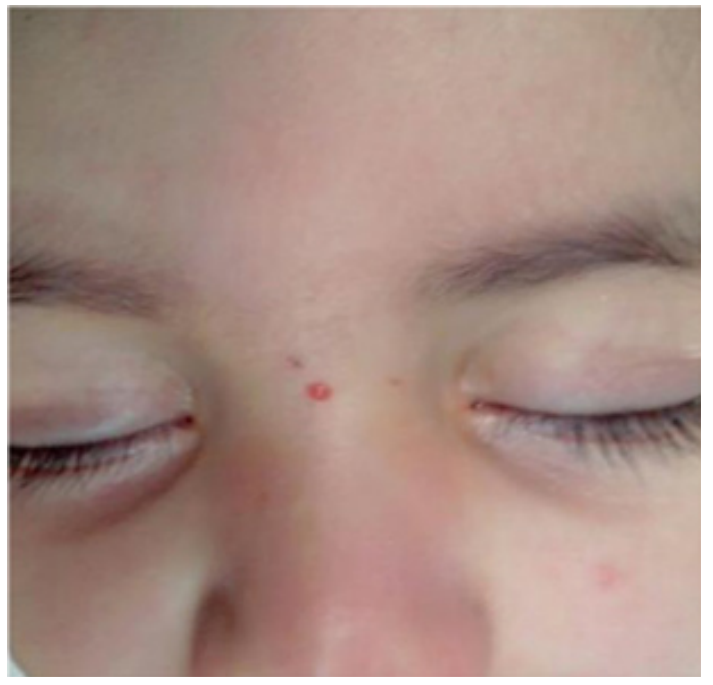

Figure I Cutaneous aspect of the nasofrontal dermal sinus as a midline nasal pit.

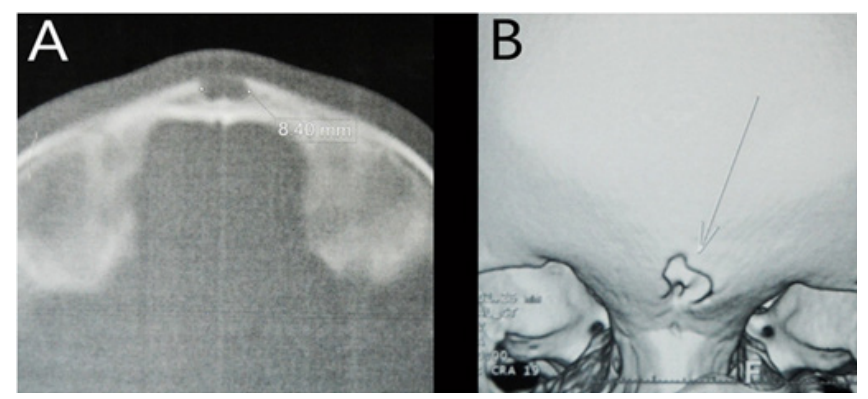

Figure 2 Axial (A) and 3D reconstruction (B) CT scan images showing an anterior midline defect of the cranial vault. 


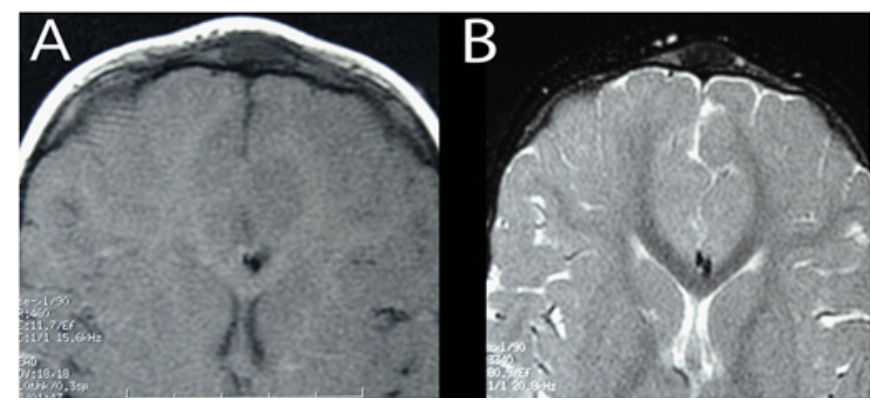

Figure 3 Axial TI-weighted (A) and T2-weighted (B) MR images showing allow signal intensity mass in the bony diploe corresponding to the epidermoid cyst.

The patient underwent a total excision of his dermal sinus along with the resection of the cyst via a trans-frontal approach (Figure 4). The inner bone layer of the skull was intact. Pathological examination confirmed the diagnosis as it showed foci of macrophagic resorptionsurrounding hair shafts and keratin lamellae. The postoperative course was uneventful.

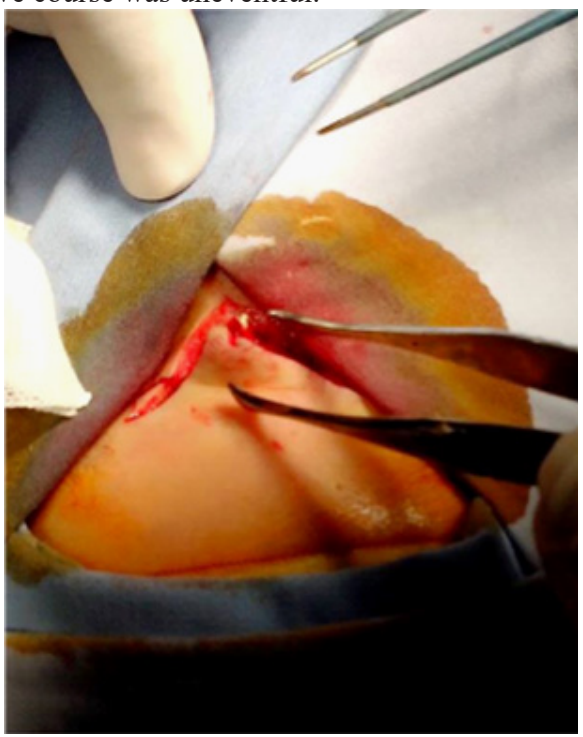

Figure 4 Trans-facial approach: exposition of the nasal lesion.

\section{Discussion}

A dermal sinus, also called a neurocutaneous fistula, is a rare malformation that occurs in one of every 20,000 births. ${ }^{1}$ A sinus tract or mass, each of which is observed in $50 \%$ of cases, is lined with a stratified squamous epithelium and may develop from the nasal base to the anterior cranial fossa ( $57 \%$ of affected patients). ${ }^{1,3}$

Neuro-cutaneous fistulas can develop anywhere along the central nervous system from the glabella to the lumbosacral region. ${ }^{4}$ however, more than $95 \%$ are located in the lumbosacral and occipital regions. ${ }^{5}$ Nasofrontal localizations are exceptional and occur in less than $5 \%$ of cases. In this location, the external orifice is usually located at the glabella. ${ }^{6}$

A Dermal sinus may be associated with ectodermal inclusions such as dermoid cysts or, more rarely, epidermoid cysts. These cysts may develop anywhere on the fistula tract; thus, they can be intracranial or extra cranial. In the present case the dermal sinus was associated to an Intradiploic epidermoid cyst which is more exceptional.

Diagnosis is usually made in infants and children. ${ }^{7}$ and only exceptionally in adulthood. ${ }^{8}$ Nasofrontalfistulas are discovered incidentally in $58 \%$ of cases. However, in one third of the cases reported in the literature, the dermal sinus is symptomatic and may be revealed by a loco-regional infection, or a non-inflammatory and nonprogressive Nasofrontal swelling suggesting a congenital anomaly, such as a cephalocele or a nasal glioma, dermoid or epidermoid cyst. However, recognition of an intermittent flow of clear fluid through a thin opening helps the diagnosis of a nasofrontal dermal sinus.

In the present case, several episodes of spontaneously regressive soft tissue swelling followed the progressive thickening of the seeping fluid without inflammatory signs. The obstruction of the fistula tract and its secondary reopening does certainly have a role in this unusual presentation. The factors associated with both mechanisms remain unresolved.

Neuro-meningeal infections complicate this malformation in approximately $30 \%$ of cases. ${ }^{7}$ and in sharp contrast to secondary infections of lumbosacral dermal sinuses usually caused by Escherichia coli, Staphylococcus aureus is the organism most often encountered in secondary infections due to craniofacial fistulas.

Conditions that may account for acute swelling accompanied by inflammation include lymphadenitis, sinusitis, odontogenic infection and abscess. Trauma can promote a secondary infection of the fistula. Whatever the mode of revelation, both CT and MRI imaging are indicated in assessing the diagnosis and seeking an associated intracranial malformation. Findings that suggest intracranial extension include bone defects, widening of the foramen cecum and a bifid or dystrophic crista galli. ${ }^{1}$ A bone window CT remains the technique of choice for visualizing bony defects of the craniofacial junction and possible associated intracranial dermoid cysts or, more rarely, epidermoid cysts, both of which appear as homogeneous hypo denselesions. ${ }^{2,9,10}$

Due to its excellent contrast resolution, MRI allows visualization of the trans-osseous channels, determination of the relationship between the fistula and the dura mater, and the distinction between dermoid and epidermoid cysts.

A dermoid cyst is more likely to be midline and fatty, hyperintense on T1- and T2-weighted MR images and it fades on the saturation of the fat signal, whereas epidermoid cysts are usually is intense to fluid on T1- and T2-weighted MR images. ${ }^{1}$ as in our case. Intracranial epidermoid cyst may mimic an arachnoid cyst. A diffusion-weighted sequence may confirm the diagnosis by showing a hyperintense mass. ${ }^{1}$

If loco regional infection occurs, ring enhancement is suggestive of an abscess. With both modalities, thin-section resolution is necessary (CT sections must be no more than $1.5 \mathrm{~mm}$ thick; MR sections should be no more than $3 \mathrm{~mm}){ }^{2}$

The only effective and permanent treatment remains surgical excision. It can be performed at the same time as for the removal of any associated abscess. Incomplete resection may lead to meningitis or recurrence, (up to $15 \%$ of cases). With intracranial involvement, intracranial and extracranial resection is required to remove the mass and its sinus tract. In all cases, perioperative antibiotic therapy should be indicated. ${ }^{3}$

In the present case the dermal sinus was associated to an Intradiploic epidermoid cyst. A minimally invasive trans-facial approach was decided and it permitted total resection of the fistula along with the epidermoid cyst. The inner layer of the skull was intact and a careful skin closure permitted a good cosmetic result. The postoperative course was uneventful. 


\section{Conclusion}

Nasofrontal swelling is a common clinical problem in pediatric population with variable causes. The knowledge of the clinical manifestations, imaging features, and the most common sites of occurrence of dermal sinuses is needed to formulate a differential diagnosis.

The case reported in this article represents a genuine example of the possible association of a nasofrontal dermal sinus with an Intradiploic epidermoid cyst and that a trans-facial approach is suitable to address the two lesions at the same time with a good cosmetic result.

\section{Ackowledgments}

None.

\section{Conflicts of interst}

None.

\section{References}

1. Lowe LH, Booth TN, Joglar JM, Rollins NK Midface anomalies in children. Radiographics. 2000;20(4):907-922.

2. Khanna G, Sato Y, Smith RJ, Bauman NM, Nerad J Causes of facial swelling in pediatric patients: correlation of clinical and radiological findings. Radiographics. 2006;26(1):157-171.
3. Hayek G, Mercier P, Fournier HD, Menei P, Pouplard D, et al. Dermal sinus and dermoid cyst revealed by abscess formation in posterior fossa. Report of 2 pediatric cases and review of the litterature. Neurochirurgie 47(2-3 Pt. 2006;1):123-127.

4. Ghestem M, Dhellemmes P, Pellerin P Congenital dermoid cysts and fistula of the nose. Apropos of 19 cases. Ann Chir Plast Esthet. 1991;36(3):183-191

5. Peter JC, Sinclair-smith C, de Villiers JC Midline dermal sinuses and cysts and their relationship to the central nervous system. Eur J Pediatr Surg. 1991;1(2):73-79.

6. Bradley PJ Nasal dermoids in children. Int J Pediar Otorhinolaryngol. 1991;3(1):63-70.

7. Hladky JP, Lejeune JP, Pertuzon B, et al. Nasofrontal dermoid fistulae and cysts. Apropos of 19 cases. Neurochirurgie. 1995;41(5):337-342.

8. Littlewood AH Congenital nasal dermoid cyst and fistulas. Plast Reconstr Surg Transplant Bull. 1995;27:471-488.

9. Baudrillard JC, Scherpereel B, Rousseaux P, et al. Rupture of an intracerebral dermoid cyst. Apropos of a case: x-ray computed tomographic aspects. J Radiol. 1986;67(2):111-113.

10. Smith AS, Benson JE, Blazer SI, et al. Diagnosis of ruptured intracranial dermoid cyst: value of MR over CT. AJNR Am J Neuroradiol. 1991;12(1):175-180 